\title{
Agronomic
}

Journal

ljê

\section{DESENVOLVIMENTO INICIAL DE MARACUJAZEIRO-AZEDO SOB DISTINTAS DOSES DE TIAMINA EM DIFERENTES TIPOS DE SUBSTRATOS}

\section{INITIAL DEVELOPMENT OF MARACUJAZEIRO-AZEDO UNDER DIFFERENT TYPES OF SUBSTRATES}

Wagner Gonçalves Vieira Junior ${ }^{1}$, Sillas Martins Mendonça ${ }^{2}$, Diogo Jânio de Carvalho Matos ${ }^{3}$, Danilo Wanderley Mendes ${ }^{4}$, Matheus Luis Oliveira Cunha ${ }^{5}$, Anderli Divina Ferreira Rios ${ }^{6}$

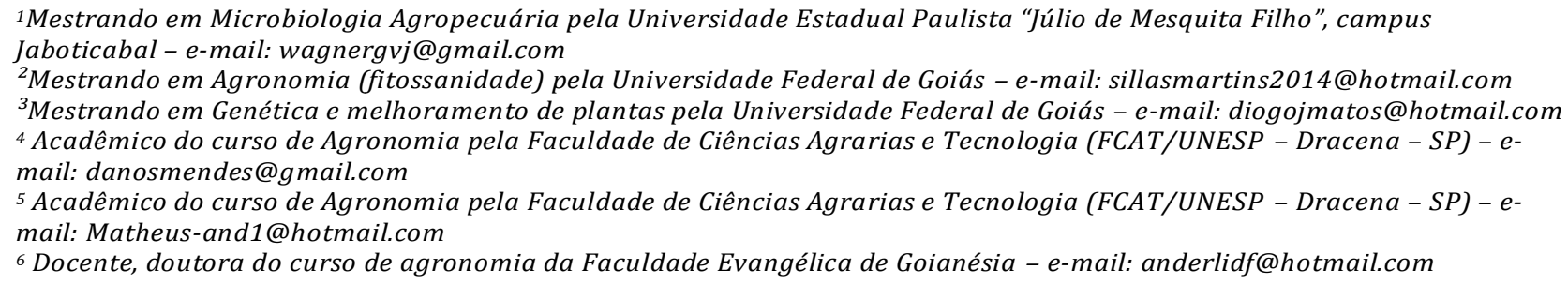

${ }^{6}$ Docente, doutora do curso de agronomia da Faculdade Evangélica de Goianésia - e-mail: anderlidf@hotmail.com

\section{Info}

Recebido: 03/2019

Publicado: 06/2019

ISSN: 2595-6906

\section{Palavras-Chave \\ Propagação de plantas, Passiflora edulis, germinação, Vitamina B1. \\ Keywords: \\ Plant propagation, Passiflora edulis, Germination, Vitamin B1.}

\section{Resumo}

0 gênero Passiflora possui um grande número de espécies, mais de 400, sendo cerca de 120 nativas do Brasil. A produção comercial de mudas de maracujá é realizada principalmente através de sementes e também através da propagação vegetativa. As plantas de maracujazeiro originadas de sementes são mais vigorosas e precoces do que aquelas provenientes de enxertia. As plantas necessitam de substratos com características físicas, químicas e microbiologia que proporcionem a semente uma germinação adequada, além de garantir o desenvolvimento da planta e de seu sistema radicular. 0 experimento foi conduzido na Faculdade Evangélica de Goianésia - Goianésia Goiás, em blocos casualizado em fatorial 4x3 com 6 repetições, sendo o primeiro fator compostos por quatro doses de tiamina (vitamina B1), sendo elas: 0mg L-1, 100mg L-1, 300mg L-1 e 500mg L-1 e o segundo fator constituído por três substratos, sendo eles: esterco bovino (solo, areia e esterco bovino, proporção de 1:2:1), cama de frango (solo, areia e esterco de frango, proporção de 1:2:1) e substrato comercial Tropstrato®. As sementes de maracujazeiro (Passiflora edulis) foram plantadas em sacos plásticos pretos de capacidade para $1 \mathrm{~kg}$. A semeadura foi realizada com três sementes por saco, posteriormente realizando o desbaste permanecendo apenas uma planta por unidade. Após 40 dias da semeadura as plantas 


\section{Agronomic}

foram retiradas do substrato, limpas e analisadas quanto á: comprimento de planta (caule e parte aérea), comprimento de raiz (final da raiz até a inserção do caule), massa fresca de parte área (folhas) e massa fresca total da planta. Verificou-se que a tiamina tem ligação com o desenvolvimento vegetativo da planta. Doses de 500mg L-1 são eficazes apenas quando utilizada junto a substrato comercial em variáveis quanto ao tamanho de planta e peso de folhas. Ao se utilizar substrato a base de cama de frango, a dose de $300 \mathrm{mg} \mathrm{L}-1$ é a mais eficaz em todas as variáveis avaliadas. Para esterco bovino a dose $100 \mathrm{mg} \mathrm{L-1}$ é mais eficaz com exceção para tamanho de planta.

\section{Abstract}

The Passiflora genus has a large number of species, more than 400, of which about 120 are native to Brazil. The commercial production of passion fruit seedlings is carried out through seeds and also through vegetative propagation. Seedlings of passion fruit originated from seeds are more vigorous and early than the species from grafting. The plants need substrates with physical, chemical and microbiological characteristics that provide an adequate germination system, besides guaranteeing the development of the plant and the root system. The experiment was conducted at Goianésia Faculdade Evangélica de Goianésia, in Goianésia Goiás, in a completely randomized design in a 4x3 factorial with 6 replicates, the first one being the component of four thiamine doses (vitamin B1): 0mg L-1, 100mg L- 1, 300mg L-1 and 500mg L-1 ejus composed of three substrates: bovine manure (soil, sand and bovine manure, ratio of 1:2:1), chicken bed (soil, sand and chicken manure, 1: 2: 1 ratio) and Tropstrato $®$ commercial substrate. The seeds of passion fruit (Passiflora edulis) were planted in black blacks with capacity for $1 \mathrm{~kg}$. The sowing was done with three seeds per bag, then performing the thinning, leaving only one plant per unit. After 40 days of sowing as plants removed from the substrate, cleaned and analyzed: plant length, root length, fresh shoot mass and total fresh plant mass. A thiamine has been found to bind to the vegetative development of the plant. $500 \mathrm{mg} \mathrm{L}-1$ doses are used when used as commercial substrate in different types of plants and leaf weight. "When using chicken bed substrate, a dose of $300 \mathrm{mg} \mathrm{L-1}$ is most effective in all variables evaluated." For bovine manure the dose of $100 \mathrm{mg} \mathrm{L}-1$ is more effective with plant size. 


\section{INTRODUÇÃO}

O maracujá-azedo (Passiflora edulis Sims) é uma frutífera que se adapta muito bem a climas tropicais e possui grande aceitação no mercado, tanto para consumo in natura como para polpas e industrialização. O brasil é o maior produtor da fruta no mundo e também o maior consumidor. No ano de 2016 em uma área de 49.889 hectares o pais produziu cerca de 703.489 toneladas do fruto (IBGE, 2017). A produção comercial de mudas de maracujá é realizada principalmente através de sementes e também através da propagação vegetativa. As plantas de maracujazeiro originadas de sementes são mais vigorosas e precoces do que aquelas provenientes de enxertia (BERNACCI, 2003; MELETTI \& BRUCKNER, 2001).

Para que a plântulas consigam se estabelecerem a germinação deve ocorrer o mais rápido possível, pois quanto maior o tempo até a sua emergência maior será sua vulnerabilidade (Marcos-Filho, 2005). Para que a germinação ocorre são necessários vários processos fisiológicos que podem ser influenciados por fatores intrínsecos (dormência, maturação fisiológica e genética) e extrínseca (luminosidade, temperatura, disponibilidade de água e substrato (Kleczewski et. al., 2010).

As plantas necessitam de substratos com características físicas, químicas e microbiologia que proporcionem a semente uma germinação adequada, além de garantir o desenvolvimento da planta e de seu sistema radicular (DE FREITAS et. al., 2015). Mudas produzidas com qualidade, quando manejadas adequadamente, podem converter-se em pomares com alta produção. Para que isso aconteça a etapa de produção da muda e

\section{de suma importância, deve ser observado:} recipientes para a produção, qualidade do substrato, qual substrato utilizar, nutrição e dentre outros fatores (MARTINS, 2007).

E meio as dificuldades para o estabelecimento de plântulas muitos mecanismos têm sido utilizados, dentre eles a aplicação exógena de vitaminas, tais como a tiamina (vitamina B1), que atua nos tecidos vegetais como cofator enzimático em vias metabólicas incluindo o ciclo de ácido tri carboxílico, glicose e ciclo de pentoses fosfato (GOYER, 2010). O efeito da vitamina reflete no crescimento vegetativo devido o alongamento celular, acumulo de reservas e melhora nas características produtivas, mesmo a planta se encontrando em condições adversas, como salinidade e déficit hídrico (ABDELHAMID et al., 2013; EL-BASSIONY et al., 2014)

A presença desta vitamina pode desencadear mecanismos de defesa contra patógenos de solo que são os principais agentes causadores de doença na cultura de maracujá (AHN et. al. 2005; BOUBAKRI et. al., 2012). Foi observador por Azhar e Khan (2015) que ao se utilizar tal vitamina, pode observar incremento nos índices de produtividade e desenvolvimento vegetativo de hortaliças.

Neste contexto, o trabalho foi desenvolvido com o objetivo de avaliar a interferência da vitamina B1 (tiamina) em diferentes tipos de substratos sobre o desenvolvimento de plântulas de maracujazeiro azedo (Passiflora edulis Sims). 


\section{MATERIAL E MÉTODOS}

O experimento foi realizado na área experimental da Faculdade Evangélica de Goianésia (FACEG) em ambiente protegido por estufa tipo arco coberta com filme PVC transparente de 150 micras. Foram utilizados blocos casualizados em esquema fatorial $4 \times 3 \mathrm{com}$ 6 repetições, sendo o primeiro fator compostos por quatro doses de tiamina (vitamina B1), sendo elas: $0 \mathrm{mg} \mathrm{L}^{-1}, 100 \mathrm{mg} \mathrm{L}^{-1}, 300 \mathrm{mg} \mathrm{L}^{-1}$ e $500 \mathrm{mg} \mathrm{L}^{-1} \mathrm{e}$ o segundo fator constituído por três tipos de substratos, sendo eles: esterco bovino (solo, areia e esterco bovino, proporção de 1:2:1), cama de frango (solo, areia e esterco de frango, proporção de 1:2:1) e substrato comercial Tropstrato ${ }^{\circledR}$. Foi utilizado solo (latossolo) de barranco extraído do perfil B, para constituir o substrato. Foram utilizados sacos plásticos de capacidade para $1 \mathrm{~kg}$, sendo semeado 3 sementes para cada e após a germinação realizado o desbaste para permanecia de apenas uma planta em cada saco.

A aplicação de tiamina foi realizada com auxílio de pipeta graduada, sendo $3 \mathrm{ml}$ por saco plástico, em 3 épocas diferentes, sendo elas: no plantio, 10 dias após germinação, 30 dias após germinação. Aos 40 dias após germinação as plantas foram retiradas do substrato e analisadas quanto a: comprimento de planta (caule e parte aérea), comprimento de raiz (final da raiz até a inserção do caule), massa fresca de parte área (folhas) e massa fresca total da planta. Para realização das medições foi utilizado um paquímetro digital 150 MM $\quad$ MTX ${ }^{\circledR}$ e para quantificação de massa foi utilizado uma balança contadora de precisão urano UA-420/0,001 420g INMETRO. A irrigação foi realizada através de micro aspersores com um total de $06 \mathrm{~mm}$ diários conforme indicado por Sousa et. al., 2001.

Os dados das coletas foram submetidos a análise de variância de regressão para ajustes de modelos que descrevam os efeitos conforme a dosagens utilizadas.

\section{RESULTADOS E DISCUSSÃO}

Para comprimento de raiz e comprimento de planta pode se observar que o tratamento utilizando cama de frango obtiveram as melhores medias, sendo que, a aplicação da tiamina potenciou as medias até doses de $300 \mathrm{mg} \mathrm{L}^{-1}$ com $15,05 \mathrm{~cm}$ para altura de planta e também para comprimento de raiz, obtendo decréscimo em doses maiores. Seguido da cama de frango o esterco bovino obteve melhores medias, sendo que para Altura de muda a concentração $0 \mathrm{mg}$ foi mais eficaz com $17,5 \mathrm{~cm}$, observando que a tiamina em substrato de esterco bovino prejudica o desenvolvimento da muda, e para comprimento de raiz a dosagem de $100 \mathrm{mg} \mathrm{L}^{-1}$ obteve o melhor resultando com media 10,35cm (Figura 01 e 02).

Avaliando substrato comercial para altura de planta, o mesmo responde até dosagens de $500 \mathrm{mg} \mathrm{L}^{-1}$ com medias de $7,5 \mathrm{~cm}$ em dosagens de $500 \mathrm{mg} \mathrm{L}^{-1}$ e para comprimento de raiz dosagens de $300 \mathrm{mg} \mathrm{L}^{-1}$ obtiveram a melhor média de $12,01 \mathrm{~cm}$, ocorrendo um decréscimo em maior concentração (Figura 01 e 02). 

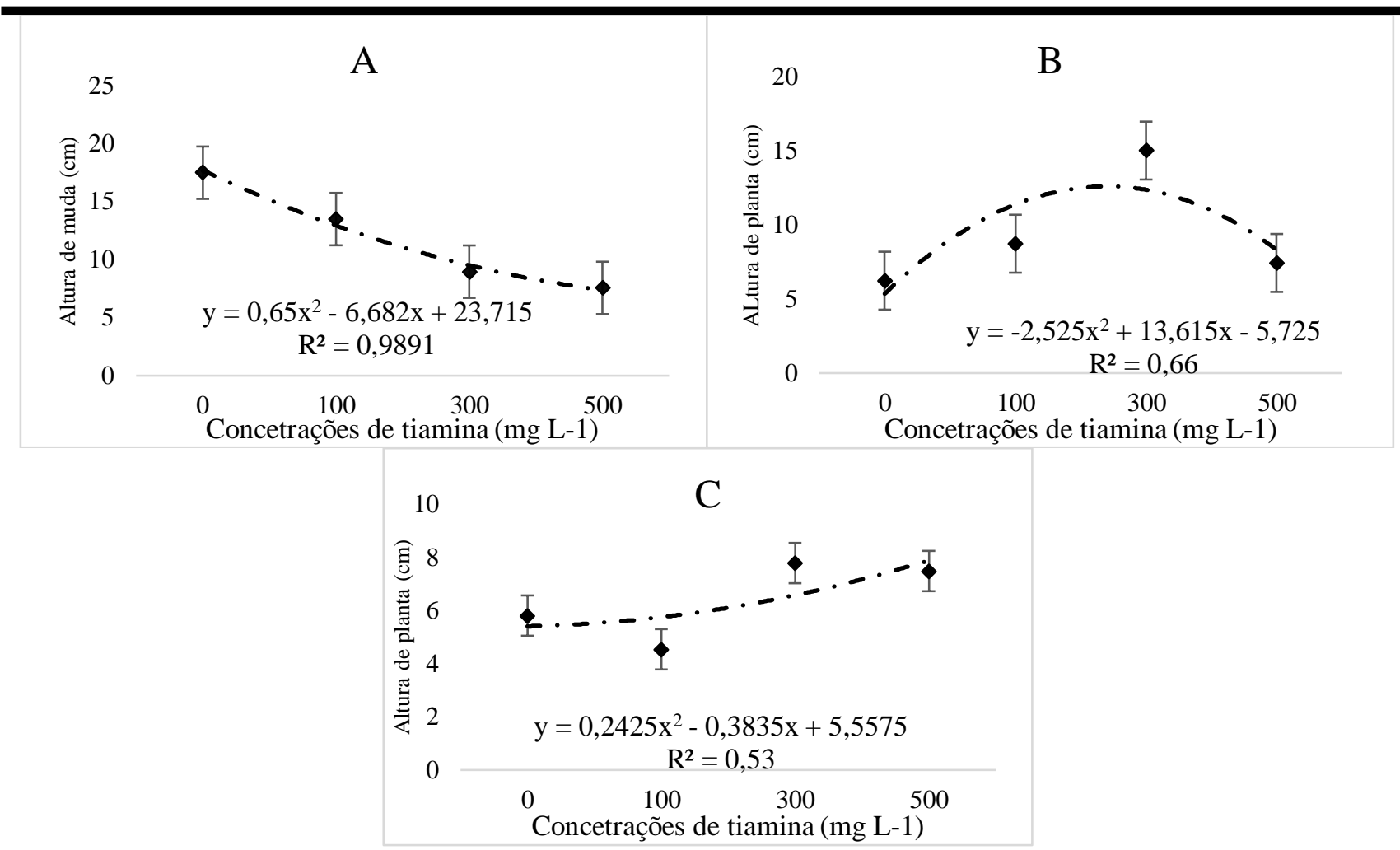

Figura 1. Altura de plantas (caule e parte aérea) de maracujazeiro azedo submetido a doses distintas de tiamina em diferentes tipos de substratos, sendo eles: esterco bovino (A), cama de frango (B), substrato comercial (C). Goianésia - GO, 2016.

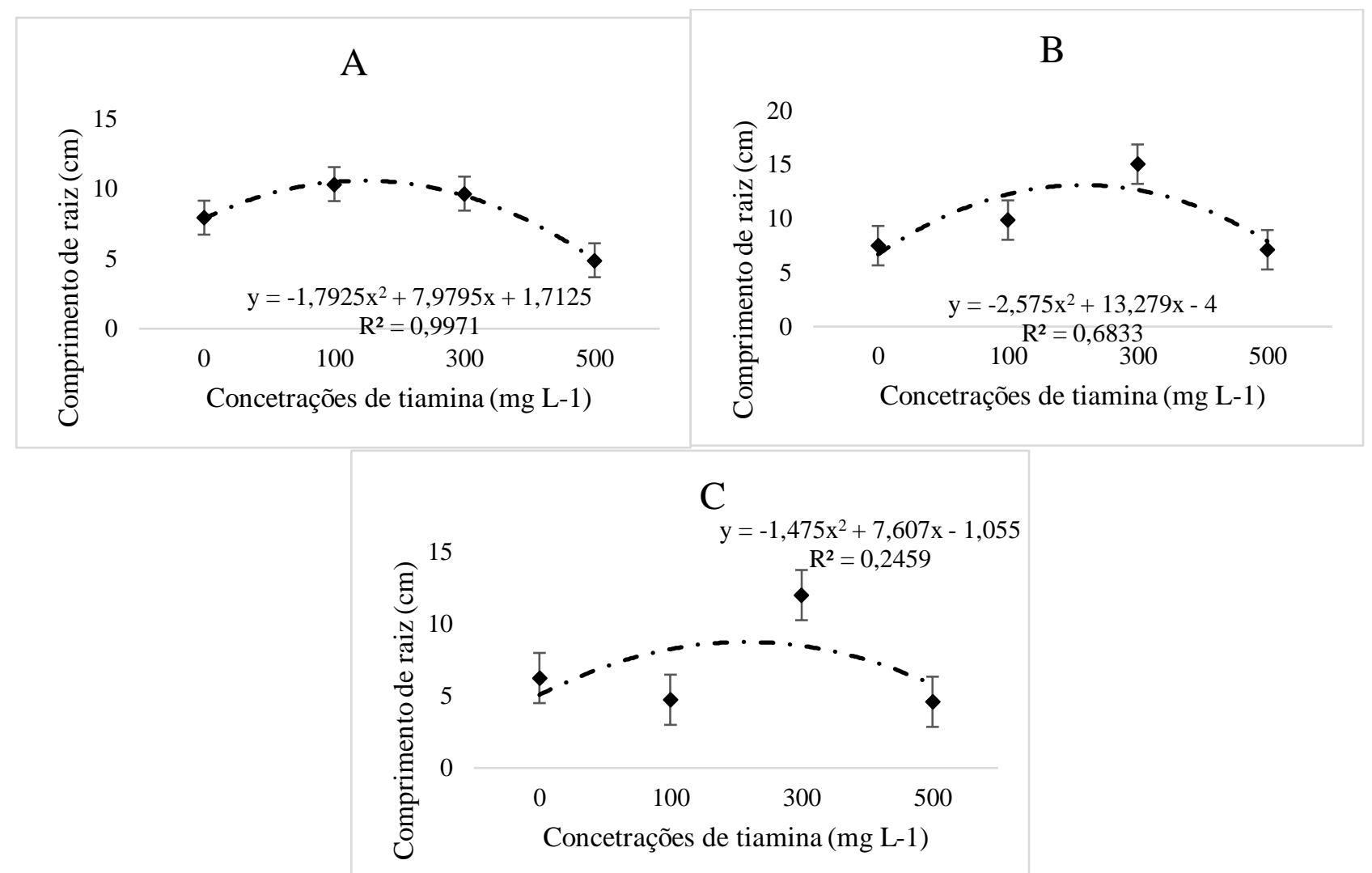

Figura 2. Comprimento de raiz de maracujazeiro azedo submetido a doses distintas de tiamina em diferentes tipos de substratos, sendo eles: esterco bovino (A), cama de frango (B), substrato comercial (C). Goianésia - GO, 2016. 


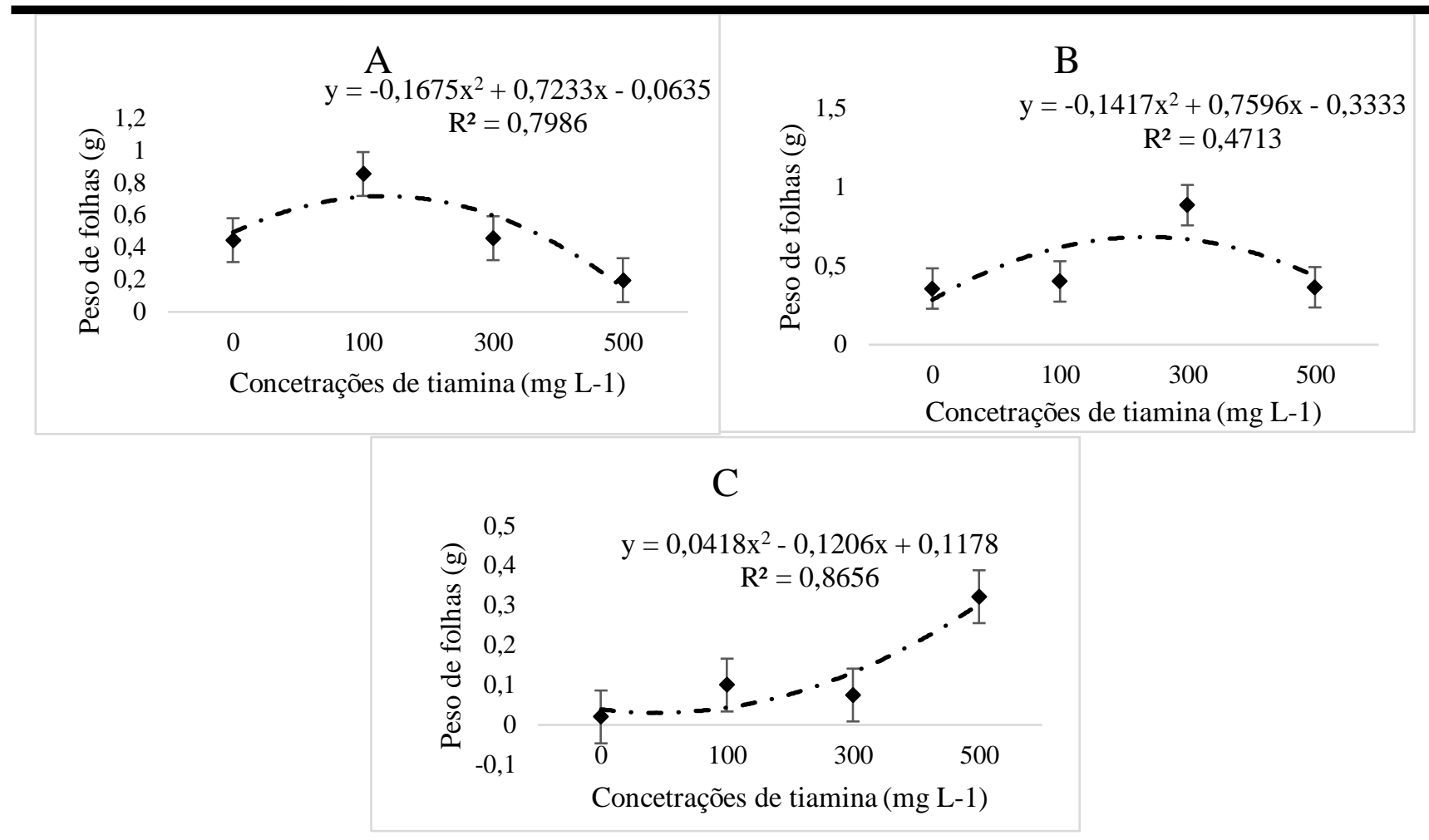

Figura 3. Massa fresca parte aérea de maracujazeiro azedo submetido a doses distintas de tiamina em diferentes tipos de substratos, sendo eles: esterco bovino (A), cama de frango (B), substrato comercial (C). Goianésia - GO, 2016.

Para massa fresca de parte área os tratamentos com substrato de esterco bovino e cama de frango tiveram as melhores medias sendo elas de: esterco bovino $0,855 \mathrm{~g}$ com doses de $100 \mathrm{mg}$ e cama de frango $0,887 \mathrm{~g}$ com doses de $300 \mathrm{mg}$, seguido do substrato comercial com maior média de $0,322 \mathrm{~g}$ em $500 \mathrm{mg}$ de concentração de tiamina. Observa-se que o substrato comercial responde a maiores doses de tiamina (até $500 \mathrm{mg}$ ) em vista do esterco bovino (até 100mg) e cama de frango (até 300mg) (Figura 03).

Ao se considerar peso de planta, observase que a cama de frango obteve maior média em comparação aos outros tratamentos, chegando a 1,925g em concentração de tiamina de 300mg, seguida do esterco bovino com maior média de 1,325 em concentração de $100 \mathrm{mg}$, posteriormente se encontrando o substrato comercial com maior média de 0,222g em concentração de 100mg. Verificando capacidade de reposta a concentrações de tiamina verifica que tratamentos a cama de frango possui maior capacidade resposta (até $300 \mathrm{mg}$ ) seguido do esterco bovino e substrato comercial (até 100mg) (Figura 04).

Verifica-se que os substratos de cama de frango e esterco bovino tiveram maior eficácia em comparação ao substrato comercial (figuras 01,02 , 03 e 04). 

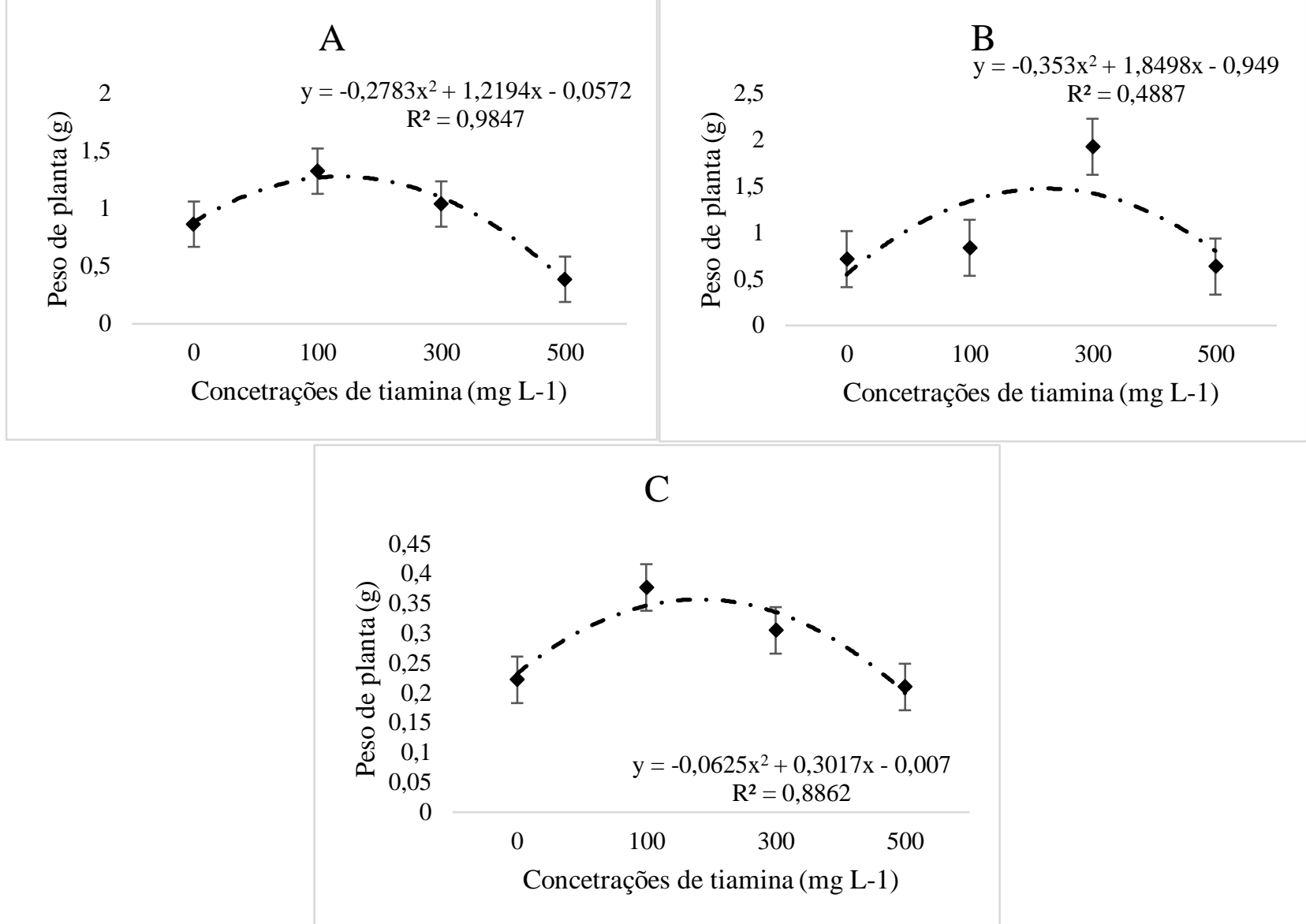

Figura 4. Massa fresca de planta de maracujazeiro azedo submetido a doses distintas de tiamina em diferentes tipos de substratos, sendo eles: esterco bovino (A), cama de frango (B), substrato comercial (C). Goianésia - GO, 2016.

Os resultados apresentados estão folhas, onde concentrações de 500mg L-1 tiveram relacionados acerca da aplicação de vitaminas para a maior eficácia em tais atributos. Observou-se incremento de produtividade e desenvolvimento também que os dados se diferenciaram ao se vegetal. Abdallah et. al. (2016) observaram na analisar doses de tiamina em substrato de esterco cultura de quinoa um incremento em de número bovino e cama de frango em todas a variáveis de folhas, comprimento da parte aérea, massa utilizadas, sendo eficazes apenas entre $0 \mathrm{mg} \mathrm{L}^{-1}$ a fresca de parte aérea, massa fresca de raiz e massa seca de raiz, utilizando concentrações de $100 \mathrm{~g} \mathrm{~L}-1$ de nicotinamida.

VENDRUSCOLO et. al. (2017) concluíram que concentrações de até 518,09 $\mathrm{mg} \mathrm{L}^{-}$ 1 são eficazes na melhoria do desempenho de mostarda crespa utilizando solo enriquecido com matéria orgânica vegetal, corroborando com os resultados que foram encontrados em substrato comercial quanto a tamanho de planta e peso de $100 \mathrm{mg} \mathrm{L}^{-1}$ ou de $100 \mathrm{mg} \mathrm{L}^{-1}$ a $300 \mathrm{mg} \mathrm{L}^{-1}$.

Os dados estão relacionados com os de ElBassiony et. al. (2014), que conclui que a aplicação de vitaminas pode proporcionar melhoras para a maximização de atividades metabólicas, consequentemente favorecendo o crescimento vegetativo através da melhora na divisão e expansão celular. Soltani et. al. (2014) também observaram que a aplicação de tiamina na cultura de margaridas, favoreceram o crescimento dos 
tecidos vegetais, aumentando a quantidade de haste florais, comprimento de hastes, massa fresca e seca das plantas.

O acumulo de carboidratos nos tecidos de plantas pode ser aumentado quando tratadas com vitaminas (SHI et al., 2002; BARAKAT, 2003; ELBASSIONY, 2005), sendo de suma importância para a manutenção dos tecidos em períodos adversos que podem ser enfrentados pela planta (PAIXÃO et. al., 2014), além do que, a tiamina e responsável de atividades metabólicas, como cofator enzimático, incluindo o ciclo de ácido tricarboxílico, glicólise, clico das pentoses fosfato (GOYER, 2010), mecanismos ligados à produção e fornecimento de energia a planta (PEREIRA et. al., 2016).

As vitaminas quando fornecidas as plantas podem agir como produtoras de metabolitos secundários, ativar mecanismos de resistência e estresses bióticos e abióticos, promovendo desenvolvimento da planta mesmo em condições adversas, e ampliando sua gama de defesa quanto a ataques de pragas e doenças (EL-BASSIONY et. al., 2014; BOUBAKRI et. al., 2012; HASSANEI et. al., 2009; AHN et. al., 2005).

\section{CONCLUSÕES}

A aplicação de tiamina elevar o crescimento e desenvolvimento vegetativo em mudas de maracujazeiro-azedo.

O substrato utilizado para plantio e desenvolvimentos das mudas interfere diretamente na eficácia da vitamina B1.

Os substratos de esterco bovino e cama de frango são mais indicados para produção de mudas de macarujá-azedo.

Doses de $500 \mathrm{mg} \mathrm{L}^{-1}$ são eficazes apenas quando utilizada junto a substrato comercial em variáveis quanto ao tamanho de planta e peso de folhas.
Ao se utilizar substrato a base de cama de frango, a dose de $300 \mathrm{mg} \mathrm{L}^{-1}$ é a mais eficaz em todas as variáveis avaliadas. Sendo para esterco bovino a dose $100 \mathrm{mg} \mathrm{L}^{-1}$ mais eficaz com exceção para tamanho de planta.

\section{REFERÊNCIAS}

AHN, I. P.; KIM, S.; LEE, Y. H. Vitamin B1 functions as an activator of plant disease resistance. Plant. physiol., Rockville, 2005; v. 138, n. 3, p.1505-1515.

ABDALLAH, M. M. S.; EL HABBASHA, S. F.; EL SEBAI, T. Comparison of yeast extract and Nicotinaminde foliar applications effect on quinoa plants grown under sandy soil condition. Int J Pharmtech Res., Mumbai, 2016; v. 9, n. 7, p.24-32.

AZHAR, S.; KHAN, S. Enhancement of Growth and Yield of Mustard (Brassica Juncea L.) Var. Varuna by Thiamine Hydrochloride (Vitamin-B1) Application. J Functi. Environ. Botany, Nova Deli, v. 5, 2015; n. 1, p.24-30.

ABDELHAMID, M. A.; SADAK MERVAT, S. H., SCHMIDHALTER, U., EL-SAADY, A. M. Interactive effects of salinity stress and nicotinamide on physiological and biochemical parameters of faba bean plant. Acta Biolo Colomb., Bogotá, 2013; v. 18, n. 3, p.499-510.

SOUSA, V. F., BORGES, A. L., COELHO, E. F., VASCONCELOS, L. F. L., VELOSO, M. D. C., DE OLIVEIRA, Á. S., \& AGUIAR NETTO, A. D. O. (2001). Irrigação e 
fertirrigação do maracujazeiro. Embrapa

Meio-Norte-Circular Técnica (INFOTECAE).

VENDRUSCOLO, E. P., DE OLIVEIRA, P. R., \& SELEGUINI, A. (2017). Aplicação de niacina ou tiamina promovem incremento no desenvolvimento de mostarda. Cultura Agronômica, 26(3), 433-442, 2017.

IBGE - Instituto Brasileiro de Geografia e Estatística. Produção Agrícola Municipal. 2016. https://sidra.ibge.gov.br/pesquisa/pam/ta belas (Acessado em 31 maio de 2019).

MARCOS-FILHO, J. Fisiologia de sementes de plantas cultivadas. Piracicaba: FEALQ, 2005. 495p.

KLECZEWSKI, N.M.; HERMS, D.A.; BONELLO, P. Effects of soil type, fertilization and drought on carbono allocation to root growth and partitioning between secondary metabolism and ectomycorrhizae of Betula papyrifera. Tree Physiology, 2010; v.30, n.7, p.807-817. http://dx.doi.org/10.1093/treephys/tpq03 $\underline{2}$

HASSANEIN, R. A.; BASSONY, F. M.; BARAKAT, D. M.; KHALIL, R. R. Physiological effects of nicotinamide and ascorbic acid on Zea mays plant grown under salinity stress. 1- Changes in growth, some relevant metabolic activities and oxidative defense systems. Res. J. Agric. \& Biol. Sci, Faisalabad, 2009; v. 5, n. 1, p.72-81.

BOUBAKRI, H.; WAHAB, M. A.; CHONG, J.; BERTSCH, C.; MLIKI, A.; SOUSTREGACOUGNOLLE, I. Thiamine induced resistance to Plasmopara viticola in grapevine and elicited host-defense responses, including HR like-cell death. Plant Physiol Biochem, Amsterdam, 2012; v. 57, n. 1, p.120-133.

GOYER, A. Thiamine in plants: aspects of its metabolism and functions. Phytochemistry, Amsterdam, 2010; v. 71, n. 14, p.1615-1624.

EL-BASSIOUNY, H. S. M.; BAKRY, B. A.; ATTIA, A. A. E. M.; ALLAH, M. M. A. Physiological role of humic acid and nicotinamide on improving plant growth, yield, and mineral nutrient of wheat (Triticum durum) grown under newly reclaimed sandy soil. Adv Ser Agric Sci, Cambridge, 2014; v. 5, n. 8, p.687-700.

EL-BASSIOUNY, H. M. S. Physiological responses of wheat to salinity alleviation by nicotinamide and tryptophan. Int J Agric Biol, Faisalabad, 2005; v. 7, n. 4, p.653-659.

DE FREITAS, A. R., LOPES, J. C., ALEXANDRE, R. S., VENANCIO, L. P., \& ZANOTTI, R. F. Emergência e crescimento de mudas de maracujá doce em função de substratos e luz. Comunicata Scientiae, 2015; 6(2), 234-240. 
diferenciada ao estresse hídrico.

MARTINS, S.V. Recuperação de matas ciliares: Enciclopédia Biosfera, 2014; v. 10, n. 19, Centro de Produções Técnicas. 2 ed. Viçosa P.255, 2007.

SOLTANI, Y.; SAFFARI, V. R.; MOUD, A. A. M. Response of growth, flowering and some biochemical constituents of Calendula officinalis L. to foliar application of salicylic acid, ascorbic acid and thiamine. EthnoPharmaceutical Products, Kerman, 2014; v. 1, n. 1, p.37-44.

SHI, H.; XIONG, L.; STEVENSON, B.; LU, T.; ZHU, J. K. The Arabidopsis salt overly sensitive 4 mutants uncover a critical role for vitamin B6 in plant salt tolerance. The Plant Cell, Rockville, 2002; v. 14, n. 3, p.575-588.

BARAKAT, H. O. D. A. Interactive effects of salinity and certain vitamins on gene expression. And cell division. International Journal of Agriculture and Biology, Faisalabad, 2003; v. 5, n. 3, p.219-225.

PAIXÃO, C. L.; JESUS, D. D. S.; AZEVEDO, A. D. Caracterização fisiológica e bioquímica de genótipos de girassol com tolerância p.2011-2022.

GOYER, A. Thiamine in plants: aspects of its metabolism and functions. Phytochemistry, Amsterdam, 2010; v. 71, n. 14, p.1615-1624.

PEREIRA, G. P.; ZANETTTE, F.; BIASI, L. A.; CARVALHO, R. I. N. D. Respiratory activity of apical meristems of plagiotropic branches of Araucaria angustifolia (Bertol.) Kuntze. Ciência Florestal, Santa Maria, 2016; v. 26, n. 1, p.203-211.

BERNACCI, L.C. Passifloraceae. In: WANDERLEY, M.G.L.; SHEPHERD, G.J.; GIULIETTI, A.M.; MELHEM, T.S. (Ed.). Flora fanerogâmica do Estado de São Paulo. São Paulo: RiMa, FAPESP, 2003. v.3, p. $247-248$.

MELETTI, L.M.M.; BRÜCKNER, C.H. Melhoramento Genético. In: BRÜCKNER, C.H.; PICANÇO, M.C. Maracujá: tecnologia de produção, pós-colheita, agroindústria, mercado. Porto Alegre: Cinco Continentes, 2001. p. 345-385. 